\title{
UAVS AND THEIR AVIONIC SYSTEMS: DEVELOPMENT TRENDS AND THEIR INFLUENCE ON POLISH RESEARCH AND MARKET
}

\author{
Cezary SZCZEPAŃSKI
}

\author{
Wrocław University of Technology, Wybrzeze Wyspianskiego 27, 50-370 Wrocław Poland \\ E-mail: cezary.szczepanski@pwr.edu.pl
}

Received 27 January 2014; accepted 20 January 2015

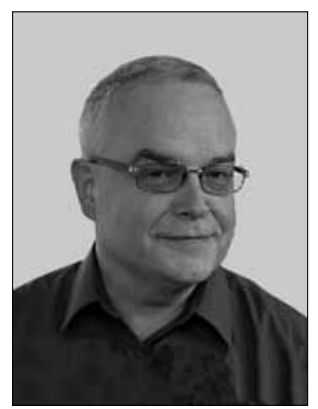

Cezary SZCZEPAŃSKI, Assoc. Prof. Dr Eng.

Education: 1980 - MSc Eng degree in aeronautics, Warsaw University of Technology, Faculty of Power and Aeronautics; 1997 - PhD studies, Warsaw University of Technology, Faculty of Power and Aeronautics, specialization: machine building and exploitation; 2005 - Dr. Sc. Eng (dr hab) Rzeszow University of Technology, Faculty of Mechanical Engineering and Aeronautics, specialization: machine building and exploitation. Affiliations and functions: 1984-2003, Warsaw University of Technology, Institute of Aerospace Technology and Applied Mechanics, adjunct professor; 1991-2004, ETC-PZL Aerospace Industries, president and CEO; 2004-2007, Polish Air Force Institute of Technology, associated professor; 2006-2008, Military University of Technology, Faculty of Mechatronics, associated professor, 2007-2008, Telecommunications Research Institute, president \& CEO; 2008-2011, Bumar Sp. z o.o., vice president, director of development; since 2009 - Wroctaw University of Technology, Faculty of Mechanics and Power, head of Department of Aeronautical Engineering, associated professor. Publications: author of 4 books and chapters in books, 23 articles, 61 conference papers, over 70 report from research projects.

\begin{abstract}
In the paper the current status of development of UAVs and their avionic systems in Poland and worldwide is presented. Technology and operation development trends, as well as key factors influencing them are described.

On this basis, research plans and suggested topics for development are proposed. The possibility of carrying them out in Poland under present conditions is taken into consideration.
\end{abstract}

Keywords: UAV, avionic systems, development, trend, design.

\section{Introduction}

\subsection{Systems}

UAV - unmanned aerial vehicles, sometimes called UAS, unmanned aircraft system, are becoming more and more significant users of aerospace. Historically, armed forces were their first users. Now, one can see a rapid increase in the number of UAV users and groups. Among them are fire fighters, police, border police and other homeland security institutions, forest administration, agricultural screening institutions, sweet water monitoring institutions, weather forecasters, advertising and promotion companies, nature preserving and ecological status monitoring institutions, aviation archaeology practitioners, pipelines and electric grid exploiting companies. This list includes only the major players in this area, whose demand for vehicles or their services has created specific types of UAVs or their payloads.

According to (Daly 2011), there are currently 318 contractors from 42 countries acting in that market, both locally and internationally. The latest edition of AIAA Aerospace America (Wilson 2013b) dated 2013.09 states, that there are 960 UAV types manufactured by 270 companies in 57 countries. So the rapid increase in the number of places and units, where UAVs are developed and manufactured, is clearly evident. The difference in the number of contractors listed by Jane's and companies listed by Aerospace America results from the fact, that the Jane's lists companies that are delivering not only the UAVs but also their elements, e.g. engines and/or payloads. In fact, the number of suppliers of complete UAS 
systems on Jane's list is lower than in the latest Aerospace America's issue.

The world leaders in UAV development, manufacturing and scope of usage are the USA and Israel. Jane's lists 98 contractors from the USA, which is the biggest number of all other countries, while Israel has the most extensive usage of UAVs, calculated in many millions of operational flight hours, flown by their UAV fleet. Those countries were also the biggest UAV exporters in the world, in 2012 Israel was the leader in that ranking. On the other hand, there are also policies of developing and manufacturing UAVs only for the country's own purposes.

In Poland, Jane's lists only 2 contractors delivering UAVs. They are: the Air Force Institute of Technology and WB Electronics S.A. In fact, they are the only companies in Poland delivering vehicles of several types, manufactured in a serial manner. There are also universities, $\mathrm{R}+\mathrm{D}$ centres and companies working on some models, technology demonstrators and prototypes of UAVs. Among them, there are: the Institute of Aviation (VTOL UAV and avionics systems), Wroclaw University of Technology (nano, micro (Fig. 1) and mini UAV),

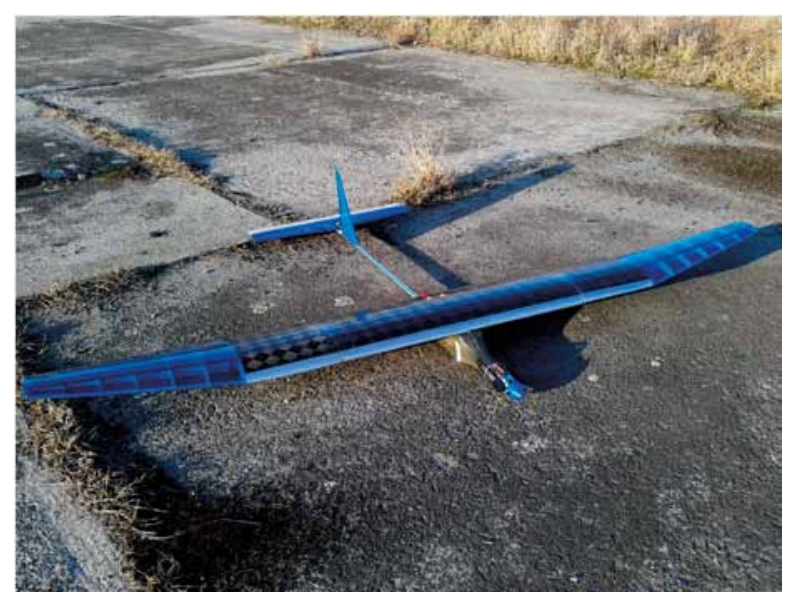

Fig. 1. A micro UAV from Wrocław University of Technology, the winner of SAE Aero Design competition in micro UAV class, in April 2014

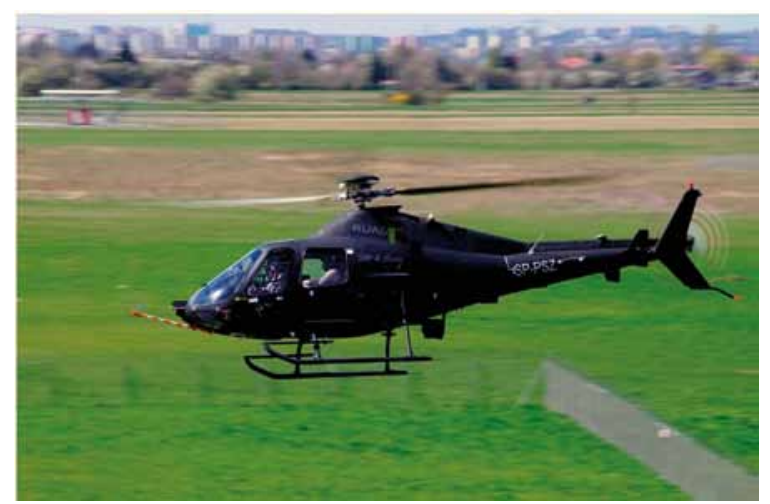

Fig. 2. Unmanned/optionally piloted helicopter "SW-4 Solo"
Rzeszow University of Technology (a few small UAVs, listed in (Agusta... 2013), and avionics systems), Poznan and Warsaw Universities of Technology (basic research on UAV and their models, and also controlling of UAV's flight in aerospace), Academy of Mining and Metallurgy (mini UAV and avionics systems). Silesian University of Technology has commercialized its research together with WB Electronics company. PZL-Swidnik SA, an Agusta-Westland company have showcased the SW-4 Solo Rotorcraft Unmanned Air System/Optionally Piloted Helicopter (RUAS/OPH) at fairs in Kielce, Poland (Agusta... 2013) (Fig. 2.).

One can make a remark, that in the European aviation sector remotely piloted and unmanned aircraft are becoming the synonym of state-of-the-art technology. We are observing an increasing number of individual hobbyist and micro-companies constructing UAV of different types, but usually micro and mini class, and offering them for local users of many kinds, like local authorities, PR companies and event organizing individuals.

The first usage experience of UAVs came from their military applications. The Israeli Air Force was the first extensive user of UAVs. They have been effectively using their UAV fleet for more than 30 years. Individual types of their most popular air vehicles have flown millions of operating flight hours. It is indicated in (Israeli... 2013) that, during the last few years, UAV sorties constituted more than $50 \%$ of all operating IAF flights. Reconnaissance operations are the most popular operations, but firing of light air-to-ground missiles and logistics missions are becoming more and more common. Other Israeli Armed Forces widely exploit loitering UAVs equipped with missiles or constituting missiles themselves. The other big user, currently the biggest user of UAVs, is the US Armed Forces. They have fielded thousands of units of different types, which have been extensively used, since the Gulf War in the early nineties. A single Predator RPA ${ }^{1}$ UAV, for example, on May the $5^{\text {th }}, 2013$, crossed its 20.000 hour of flight in Afghanistan starting from October 2004, out of which 95\% were operational flights (Single... 2013). Other missions are performed by several specialized UAVs (Airmen... 2009): from dual-missions of close-air support and ISR tasking, lasting over 12 hours at an altitude above 50.000 feet, which are performed by MQ-1 Predator and MQ-9 Reaper, ISR missions, similar to the previously mentioned, by RQ-4 Global Hawk, to missions performed by a tactically armed, tube-launched Switchblade with a total weight of $2.5 \mathrm{~kg}$. Each division of the US Armed Forces has their own specialized types of UAVs, able to perform specific tasks. In Europe, the United Kingdom's armed forces is a massive user of UAVs is, with

\footnotetext{
$\overline{1 \text { Predator number }} 107$ (P107)
} 
their 500 UAVs (British... 2013). They exploit several types of systems, starting with the Reaper, armed with Hellfire missiles and laser-guided bombs, to the Black Hornet mini-helicopter, which can fit in a hand, with the Hermes 450 surveillance drone which will be replaced by the new Watchkeeper, in between. Operational use of UAS increased substantially during the last five years. In 2008, there were 296 missions in Afghanistan and one or more missiles were deployed by a British-operated Reaper in 14 missions, which is 5 per cent of the total number of sorties. In 2012, there were 892 missions, with weapons being fired on 92 occasions, which amounts to more than 10 per cent of all sorties. In Poland, with the exception of aerial targets, only tactical reconnaissance UAVs is used. Lately, Poland has joined the NATO program of Euro Hawk (Poland... 2013), which concerns RQ-4 Global Hawk Block 40, radar-equipped UAVs. Poland became the $15^{\text {th }}$ country in that Alliance Ground Surveillance programme.

\subsection{Avionics}

Avionics systems applied into UAVs were adapted from standard aviation avionics. In fact, the majority of those systems are similar or exactly the same. Only specialised requirements for UAV systems caused the development of some avionics systems dedicated to UAVs. Among them there are: communication and data transmission systems, autopilots, observation and reconnaissance systems. Other avionic on-board systems, such as power supply, armament control, navigation, are the same or very similar to their manned aviation counterparts. In general, one can say, that UAV dedicated avionics systems are lighter, more compact and simpler that their manned aircraft versions. Very often they are not doubled nor manufactured according to aerospace standards. These remarks are valid particularly for small UAV equipment, whose operational flight time is short (less than 1 hour) and the probability of loss is comparatively high. Such UAVs need to be cheap and easy to replace. Their on-board avionics systems constitute the majority of their price, so usage of COTS equipment, which is easily available and cheap, is a standard for such UAV constructors.

From the avionics point of view, the most interesting part of on-board equipment are IMUs (inertial measurement units) very small, packed in one chip combined with the GPS signal processor (Fig. 3), the micro-technology for positioning, navigation and timing (Micro-PNT) without a GPS (DARPA's... 2013), multi spectral observation systems (day and night) EO/IR, e.g. (Hood... 2013), video tracking systems (GE Introduces... 2013) and radars. This equipment is sometimes designed and manufactured by companies which have been active in non-aeronautical fields, such as medicine,

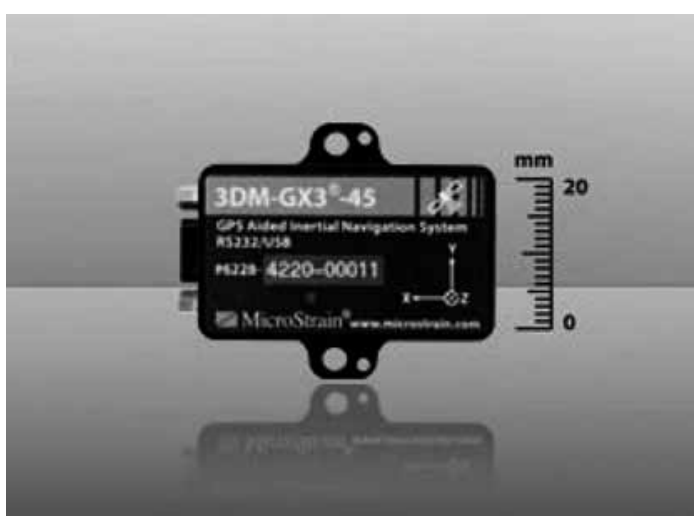

Fig. 3. 3DM-GX3-45-miniature-GPS-aided-inertial-navigation-system

ground vehicles, optics, image processing, etc. Since specific aeronautical requirements do not apply to them because of low level flights performed by small UAVs, the avionics equipment uses solutions developed for other applications, which are manufactured in high-volume numbers, and are, therefore, cheap. This promotes the use of such devices, which is the basis for emerging new operational areas for UAVs.

\subsection{Law}

There is no law, in any country, defining the conditions of flying a UAV in controlled aerospace together with manned aircraft. In Europe's legislative network, UAVs or rather RPASs (remotely piloted air systems), are divided into two major groups, each regulated by different authorities. UAVs of TOWs over $150 \mathrm{~kg}$ are regulated by the European Aviation Safety Agency (EASA), while light ones fall under national competence. In consequence, a set of European and national rules need to be developed and harmonized as far as possible "in order to ensure a true single market for aerial services" (Roadmap... 2013). In Poland the UAVs not exceeding the total weight of $32 \mathrm{~kg}$ can fly at altitude below 1000 feet without any restrictions, unless some special rules are introduced related to a certain area.

In the USA the Congress set September the $30^{\text {th }}$, 2015, as the Federal Aviation Administration target date to safety integrate UAVs into the national airspace. According to FAA estimation, there could be as many as 7.500 drones in commercial use in the USA within five years. Therefore, it seems that it is very necessary to comply with the target date.

In Europe, a European Union's roadmap has been developed in order to achieve the above mentioned goal. It aims to provide a clear strategy, define the priorities and describe concrete tasks with respect to the three main areas: aviation regulation, technology and societal impact, i.e. data and privacy protection, insurance and liability. As a consequence, within the $7^{\text {th }}$ Frame 
Program some research projects concerning UAV have been funded, in order to achieve the previously defined tasks. The EU provides funding for the following areas of UAV application: precision agriculture, infrastructure inspection, wind energy monitoring, pipeline and power inspection, highway monitoring, natural resource monitoring, environmental compliance, atmospheric research, media and entertainment, sports photos, filming, wildlife research, hunting and anti-hunting monitoring, disaster relief. In the EU Commission policies the time frame for establishing a common controlled air space has been established as follows: "After completing an extensive set of consultations with the Member States and other European stakeholders on the future of RPAS the Commission is now preparing a roadmap for safe RPAS integration into the European airspace system from 2016" (Roadmap... 2013; European Commission 2013).

Polish Civil Aviation Authority has created a working group dedicated to solving this problem. It consists of representatives of institutions involved in UAV development, exploitation and air space control: the Agency of Home Security (ABW), Polish Air Force, Bialystok University of Technology, Gdansk University of Technology, Poznan University of Technology, Aviation Institute and Polish CAA. During the group's last meeting ${ }^{2}$ the decision to prepare a valid order of the Polish Ministry of Transportation has been made. The deadline for implementation of such a decision and inclusion of UAVs into the controlled air space has been set for the end of 2016 .

Operational flights of UAVs in controlled air space are subject to individual approval. All countries should include such rules in their regulations, like the USA (U.S. Department... 2013). The key to obtaining approval from regulatory agencies is a proven "sense-andavoid" capability to prevent collisions with other aircraft.

\section{Trends}

One can easily see the rapid changes which take place in UAV aviation. They cover almost every aspect, including users, operation, development and technology. Some of them result from general changes in our society and technology, but others are specifically UAV connected. The most important ones for UAVs are discussed in the following part of this paper.

\subsection{Specialization}

The trend of specialization of UAV functions and tasks has resulted in the fact that, at present, no new universal systems have appeared. Universal here means that the same system can be used by different users and/or for different applications. Even the same type of UAV,

226 March 2013 at ULC http://www.ulc.gov.pl/index.php?option=com_content $\&$ view $=$ categor $y \& i d=346 \&$ Item id=1504\&lang $=$ pl e.g. Israeli Heron or its US twin, has its versions dedicated to Army and Navy. Those differences can be seen in the fuselage structure, power plant, on-board avionics equipment, and other payload.

Specialization is reflected in the UAV's structure, size and cost. All those aspects can be optimized according to a predefined, narrow range of functions and tasks, to be performed by the system. Furthermore, it allows reducing the price of such a UAV, particularly if its manufactured in a serial manner. An example of such a system could be any of the so called loitering UAVs, which are specialized flying munitions, able to search, identify and destroy previously defined targets, such as the Israeli "Harop" or the US "BattleHawk" (US Army... 2013). Specialized UAVs are also used in civil applications, among them there are nano, micro and mini devices, like RoboBee (Eshel 2013) or ScanEagle (ScanEagle... 2013) (Fig. 4), able to fly in specific environment and perform reconnaissance.

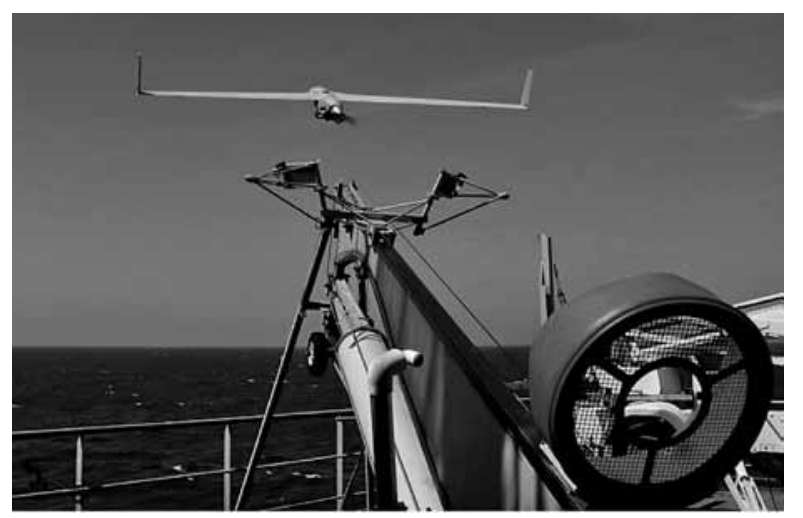

Fig. 4. ScanEagle UAV monitoring arctic waters

\subsection{Automation}

Automation in UAVs means not only the ability to perform flights in autopilot mode during certain flight mission stages, but also performing the mission tasks in this mode. Another achievement of this trend is mission tasks performed completely in automatic mode by a group of cooperating UAVs. A military area example could be a mission consisting of searching, reckoning, identifying and destroying the object located somewhere within a previously defined range. Such a task was performed almost two years ago by a group of a few UAVs, among which there were ISR, communication relay and armament equipped devices. They found, identified and then destroyed a car parked at a parking lot, among other vehicles, without any control from the mission control centre. The UAV group transmitted information on mission performance in on-line mode, which allowed eventual correction of mission participants' action by the ground human controller. Another example of general importance for aviation is in-flight refuelling. Such a mission has been successfully completed by UAVs in an 
independent mode. For the first time at the end of 2008 (Warwick 2008) a fully autonomous rendezvous and docking was performed, but it did not involve actual fuel transfer. It was mastered in complete sequence with a real fuel transfer between UAVs in 2012.

\subsection{Design variety}

UAV design variety is closely related to the specialization of systems. New structures and ideas for lift force sources and their layout will probably appear and be proposed the range of when UAV functions is extended. The following types of UAV, perform typical missions and tasks, both in military and civil areas:

- Reconnaissance of class:

- HALE - High Altitude Long Endurance (altitude over $7000 \mathrm{~m}$ and time of flight - over $8 \mathrm{~h}$, maximum - over $50 \mathrm{~h}$, at present); they are of strategic and operational levels;

- MALE - Medium Altitude Long Endurance (altitude - 300 to $7000 \mathrm{~m}$, and long endurance of flight); it is in operational level;

- Tactical - performing flights at altitudes up to $3000 \mathrm{~m}$, in an operational radius up to $20 \mathrm{~km}$;

- Local - performing flights at altitudes up to 300 $\mathrm{m}$, within time up to $1.5 \mathrm{~h}$;

- Mini, micro, nano - with total weights from 10 grams up to $1 \mathrm{~kg}$, performing flights within the time from a few to over a dozen minutes, often within buildings.

- Armed:

- Flying munition, so called loitering UAVs, searching for targets and, after confirmation from ground control centre, hitting them by themselves;

- Armed versions of big reconnaissance UAVs, able to fly with classic missiles and guided bombs, acting like the above mentioned loitering systems;

- Detecting and destroying land mines - the newest type of UAVs. They have the shape of a single rotor NOTAR helicopter.

- Flying targets - powered with a rotor, jet or rocket engines, performed flights on a predefined path, with a predefined velocity. Such tasks could also be used for many civil applications.

- Transport - most often manned helicopters transformed into a UAV or rather OPAV (optionally piloted aerial vehicle), used for automatic delivery of cargo required at danger zones.

- Complex tasks, performed by groups of UAVs, in autonomous mode. Those groups consist of the above mentioned UAVs equipped with the systems dedicated to specific tasks to be performed. The group of UAVs is listed here as a type because it is a unit which cannot be used effectively without any of its element vehicles.
That last part shows the latest trends, which result in intensive development of UAV systems and their applications. It results in new areas of air operations and activities not yet connected with such abilities.

\subsection{Increase the number of suppliers}

In the last years there has been a substantial increase in the number and groups of UAV developers, as well as in the aspects of their location and also their type of activity. Except for traditional suppliers of UAV, like Israel, which is the world's largest exporter of unmanned aircraft systems in terms of volume, variety of systems, as well as the number of countries to which these items were sold over the past decade (Frost... 2013), and the USA, new countries are now offering their systems for exportation or developing them for their home use. Such a trend is seen not only in the countries with a strong tradition in the aviation industry, but also in those countries which have had no such assets or are poorly developed from the industrial point of view. Colombian VTOL "Chronos" (Fig. 5) could be seen as such an example, with covert equipment for use by special forces' personnel and for agricultural, industrial applications (New... 2013), and Nigerian Amebo III "designed to enhance aerial surveillance capabilities of the Nigerian Air Force" created by several MSc students of Nigerian Air Force Institute of Technology, with support from UK Cranfield University (Nigerian... 2013). In countries with a well-established aviation industry, spin-off companies dedicated to a single idea from the UAV technology area are appearing. They are offering new design UAVs, new concepts of control, avionics or payload systems. When they become a successful business very often they are acquired by large aerospace companies.

That trend can be summarized as: everybody wants to have his/her own UAV (Wilson 2013a), which now becomes feasible even for individuals at their homes (DIY... 2013).

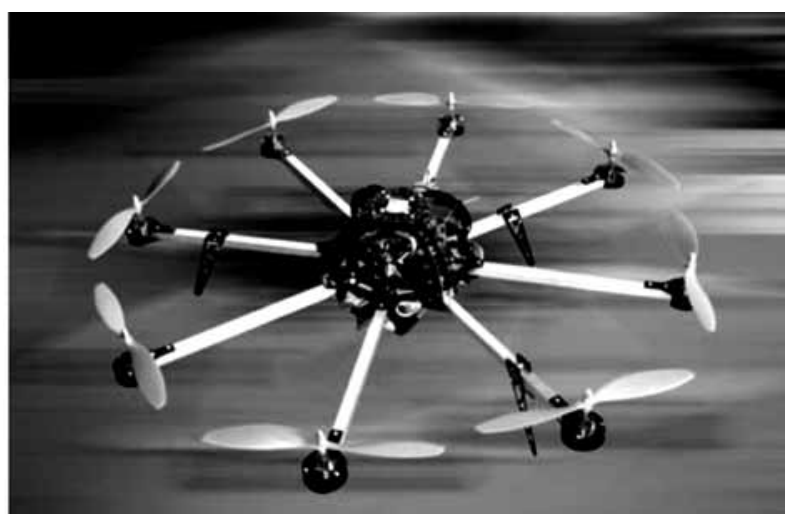

Fig. 5. Colombian UAV "Chronos" 


\section{Factors influencing trends}

\subsection{New applications and users}

New applications and users are connected with the UAV technology becoming more mature, its popularization and the decreasing of its cost. New application areas can be found both in military and civilian areas. In the military the areas are land mine hunting, escorting and monitoring operations of other elements, providing auxiliary infrastructure, scanning routes, spotting IEDs and providing communication relays, interception or air-to-air and air superiority missions (Unger 2013). In civilian areas the developments are viewed in firefighting (Oklahoma... 2013) and police missions, and purely civilian missions such as weather research, oceanographic and polar exploration, agricultural (Nigerian... 2013) and forest monitoring (UAS... 2013b), advertising and hobbies (aerial photography), aerial archaeology (UAS... 2013a), etc.

New users are emerging from new application areas. The biggest in number are scientific institutions, such as universities or specialized research centres, news agencies, TV networks, pipeline and grid exploiters, filmmakers. Among the new users there are some unique ones, such as wildlife observers (Vermeulen et al. 2013; Idaho Power Company 2013), UN organizations (UN... 2013), mountain rescue services (UAS... 2013c), courier service companies (Autocopter... 2013). Such an explosion in the demand and production of UAVs for non-military applications is certain to become a new driving force for advancing UAV technologies. On the other hand, it will generate debate on privacy and safety issues and put pressure on lawmakers to respond.

\subsection{Technology development}

The main areas of technology influencing the development of UAV trends are composite materials and their application techniques, and also payload. Modern composite materials have become standard for UAV fuselage construction. The latest achievement here is $3 \mathrm{D}$ printing of UAV structural elements.

The key technology factor influencing UAV development trends is payload, including on-board avionics systems. Inside this group there are some areas, which could be treated as crucial for new applications and designs.

- Dissemination of sensors and devices built in MEMS technology, e.g. (Epson... 2013; Silicon... 2013).

- Miniaturization of observation systems: optical, infra-red, radar (SAR, ISAR), e.g. (Micro-Epsilon... 2013).

- Common availability of satellite communication for commercial and private users.
- Substantial capacity increase of communication and data transmission systems.

\subsection{Dissemination of UAV}

That dissemination of UAVs has been analysed and discussed in previous parts of the paper, together with new applications and te users. The dissemination factor also covers the case, when only the number of units is increasing, without new users or applications appearing. This is the most common situation, as more experienced users are able to validate the results of applying UAV technology to their activities. An extensive increase in operational UAV numbers proves their effectiveness and functionality.

Development of UAVs and their equipment markets caused substantial decrease in their prices. It has increased the availability of this technology for an extended range of users, which in consequence has broadened and deepened the market. It is a kind of self-powered system.

\subsection{Technology availability}

Comparatively easy access to technologies connected with the construction and exploitation of UAV allows an explosive increase of designers and manufacturers of unmanned systems. Very often advanced hobbyists are able to design and construct or rather integrate quite complex and sophisticated units. For less advanced ones, there are offers for UAV's in kits for home integrating (DIY... 2013). The same situation can be seen in the case of on-board equipment, like day light cameras, where standard devices are successfully applied to amateur photographing and footage of private events.

\subsection{Law and societal aspects}

Lack of laws allowing high altitude flying of civilian UAVs is still keeping them out of common use. Plans for introducing such a law by the end of 2016 in most of the developed countries gives the hope for a quick development of UAV technologies and applications. Although, it brings into focus the problem of observing privacy in everyday life. People protesting against breaking of privacy rules are preparing themselves for fighting for their rights already. Such a fight could now look rather funny, like in the case in (Deer... 2013), where licenses for hunting UAVs are given to citizens of one of Colorado's cities, but in the future this could be more serious. Safety issues, which are brought into focus by some lawmakers, should also be of interest to the industry. As long as potential accidents are connected with conscious UAV users, e.g. (Model... 2013), where a UAV beheaded its user, there will be no further consequences. If they would involve other persons, then serious problems could arise for all UAV market players. 


\section{Polish UAV market and R\&D}

Polish assets in the UAV field have been listed in the previous paragraph of the paper. The conclusion is that UAVs and their applications are underdeveloped for a country of Poland's size and technological level.

The potential market for UAV's in Poland is huge in both military and civil areas. All kinds of Polish armed forces should have in their inventory a much bigger number of UAVs of many kinds, dedicated to different missions and tasks, to be performed in different environments (Fig. 6). Similar situation exists in police, boarder police, fire fighting and other institutions responsible for crisis management and home security. Civilian users, such as state forest administration, agricultural administration or companies exploiting pipelines and grids, are next potential clients for specialized UAVs. Even the services listed here, potential clients for big UAVs able to perform the long lasting flights, could exploit hundreds of units, in total. We can easily add to that account hundreds of small size and shorter time of flight systems, which could be used by local authorities, companies and private persons. After a proper law comes into force, allowing civilian UAVs to fly in controlled air space, one can expect an explosive increase in UAVs' number and types in Poland. That demand should be, in the author's opinion, fulfilled by local developers and suppliers of UAV systems, particularly of small sizes. All trends and factors discussed above, as well as the aerospace technology level and general technology level in Poland show that this is probable.

Polish research and development trends in UAV technology area reflect the developments which are seen in Europe (European Commission 2013) and the rest of the world (Sweetman 2013). A list of key areas for development and research is provided below.

- Power source: solar, diesel engines, fuel cells, all electric vehicles, hybrid power unit.

- Different ways of achieving vertical take-off and landing: hybrid power unit, where electrical engines powered by a piston one drive the rotors directly, tail sitting vehicles, the hot-cycle tip-jet ${ }^{3}$.

- Avionics and payload: on-board electronically scanned array radars, small integrated EO/IR stabilized observation turrets, small high resolution SAR and ISAR radars, generally "longer range, higher resolution, 'platform-agnostic' ISR sensors” (US Air... 2013).

- Transforming manned aeroplanes and helicopters into OPAVs, planned, performed or only studied for: Gripen (Gripen... 2013), F4 (Host

\footnotetext{
3 A simple gas-turbine engine is mounted on the rotorhead and an exhaust is ducted along the blades to nozzles in the tips. An ATRO-X helicopter type UAV.
}

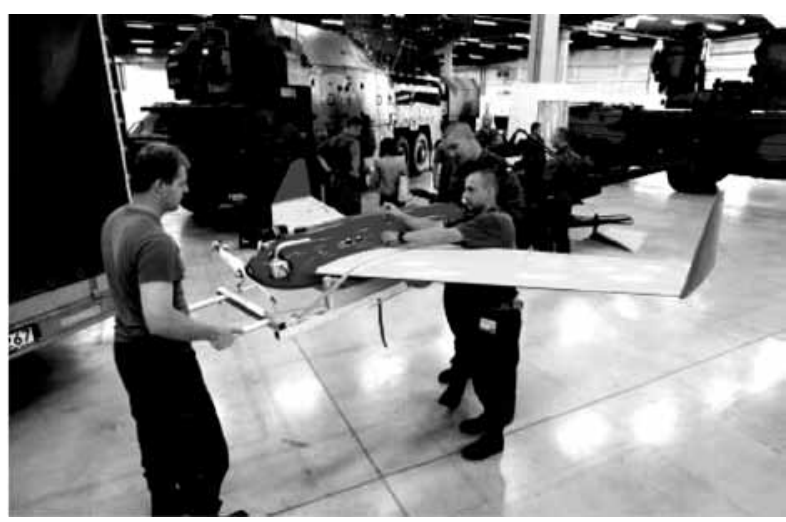

Fig. 6. Flying target "Szerszeń" made by the Polish Air Force Institute of Technology

2012), helicopters: Little Bird (MD500 in origin) (McCarthy 2012), Kaman K-max, Berkut VL (UAE... 2013), SW-4 (Polish... 2013).

Social trends connected with UAVs are also appearing. One of them is the development of social networks for UAV users and/or hobbyists, like Dronestagram (Dronestagram... 2013). It is a social network for UAV owners to share their aerial photos of cityscapes, countryside, sporting and other kind of events. Another trend is associated with replacing the broadly used terms UAV or UAS, which have bad connotations related to in combat usage of those vehicles, with the term RPAV (remotely piloted air vehicles). This would allow minimizing or even getting rid of citizens' fear that autonomous flying robots could injure or kill them and damage or destroy their homes.

In Poland of the development of UAVs started in the nineties. Many of the units were designed and built by $R \& D$ centres and technical universities, but none of them were commercialized and fielded. Currently, the same institutions are working out new UAV designs, their control systems, avionics, and payloads (mainly for observation). There are attempts to complete the development process and fielding of such systems, which unfortunately are not strongly supported by potential stake holders of UAV systems. More hope for completing the process is for the SW-4 SOLO OPAV being developed by "Agusta-Westland Company" - WSK Swidnik, on the base of its SW-4 manned helicopter. Although there is a Polish MOD's R\&D program for military UAV development which is of high priority, the financial conditions and decision on introducing the above mentioned Euro Hawk into the service are not indicating a promising future.

\section{Conclusions}

The paper describes trends of UAV market development and also factors influencing them that are a worldwide standard. Thanks to globalisation of information, technology, trade and peoples' aspirations, we can see very 
similar unmanned aircraft indigenously developed and used in many countries. For the majority of UAV types, their development and exploitation costs are reasonable, which allows for their widespread use. While considering non-profit R\&D devices or units built for non-commercial usage, we do not need to think about their technical and commercial effectiveness. For commercially produced systems this is a must. In such cases, each developer or even each country should establish their specialisation in the UAV area, keeping in mind that this market is of a world-wide size. Tough competition in the market will not permit the existence of ineffective manufacturers or systems. The proper choice of such a specialisation is a basis for a successful future.

Taking into consideration the strengths and capabilities of Polish R\&D centres, the demand from potential clients and the competition within this market, the best directions for UAV development could be chosen. In the author's opinion, the following directions for future $\mathrm{R} \& \mathrm{D}$ work that would be potentially successful from the scientific and the market point of view in Poland are:

- Micro, small and medium size UAVs for any kind of users.

- Observation and ISR systems including UAVs for military and civil applications.

- Software for group actions of UAVs.

- Specialized on-board sensors and software for their integration.

- Specialized avionics devices with software.

After successful R\&D, manufacturing of the above mentioned items to satisfy a global market demand scale would be reasonable and potentially could bring expected results.

\section{References}

Agusta Westland Subsidiary Showcases Solo Rotorcraft UAS/ Optionally Piloted Helicopter [online]. 2013 [cited 01 July 2013]. Available from Internet: http://www.uasvision. com/2013/09/05/augusta-westland-subsidiary-showcases-solo-rotorcraft-uasoptionally-piloted-helicopter/

Airmen demonstrate unmanned aircraft not merely "drones", UAS Vision Daily News. 2009. March.

Autocopter announces UAS designed for agricultural applications, UAS Vision Daily News [online]. 2013 [cited 01 July 2013]. Available from Internet: http://www.uasvision. com/2013/07/01/autocopter-announces-uas-designed-foragricultural-applications/

British Military now has 500 UAS, UAS Vision Daily News [online]. 2013 [cited 08 May 2013]. Available from Internet: http://www.uasvision.com/2013/05/08/british-militarynow-has-500-uas $/$ ?utm_source $=$ Newsletter\&utm_medium=email\&utm_campaign $=$ e9799b3cc4-RSS_EMAIL_ CAMPAIGN\&utm_term=0_799756aeb7 -e9799b3 cc4-297544857

Daly, M. (Ed.). 2011. Jane's Unmanned Aerial Vehicles and Targets, Issues Thirty-Six. Jane's Information Group. ISSN 1748-250X.
DARPA's micro-technology for positioning, navigation and timing (Micro-PNT) without GPS, UAS Vision Daily News [online]. 2013 [cited 18 April 2013]. Available from Internet: http://www.uasvision.com/2013/04/18/darpas-micro-technology-for-positioning-navigation-and-timing-micro-pnt-without-gps/?utm_source $=$ Newsletter\&utm_medium $=$ email\&utm_campaign $=$ dfda918be 0

Deer trail clerk returning cheques for UAS hunting licences, UAS Vision Daily News [online]. 2013 [cited 09 September 2013]. Available from Internet: http://www.uasvision. com/2013/09/09/deer-trail-clerk-returning-cheques-foruas-hunting-licences

DIY (drone it yourself) UAS in a box kit, UAS Vision Daily News [online]. 2013 [cited 08 July 2013]. Available from Internet: http://www.uasvision.com/2013/07/08/diy-drone-it-yourself-uas-in-a-box-kit/?utm_source=Newsletter\&utm_medium=email\&utm_campaign=b1b496c637-RSS_EMAIL_ CAMPAIGN\&utm_term=0_799756aeb7-b1b496c637297544857\#sthash.xlYF7h5C.dpuf

Dronestagram social network site for sharing for aerial pictures, UAS Vision Daily News [online]. 2013 [cited 25 July 2013]. Available from Internet: http://www.uasvision. com/2013/07/25/dronestagr-am-social-network-site-forsharing-for-aerial-pictures

Epson Electronics America, Inc. 2013. Inertial Measurement Units (IMU), Inclinometers \& Accelerometers [online], [cited 06 September 2013]. Available from Internet: http://www. unmannedsystemstechnology.com/2013/05/epson-electronics-america-inc/?goback=\%2Egde_896357_member_271553189\#\%21

Eshel, T. 2013. Insect Size RoboBee Performs Controlled Flight [online], [cited 11 May 2013]. Available from Internet: http://i-hls.com/2013/05/insect-size-robobee-performscontrolled-flight/?goback=\%2Egde_896357_member_240085345

European Commission. 2013. Flying New Way. Enterprise and Industry. Remotely Piloted Aircraft Systems, a Boost for European Creativity and Innovation [online], [cited 07 May 2013]. Available from Internet: http://ec.europa.eu/ enterprise/sectors/aerospace/uas/index_en.htm

Frost \& Sullivan: Israel is the World's Largest Exporter of Unmanned Aircraft [online]. 2013 [cited 21 May 2013]. Available from Internet: http://i-hls.com/2013/05/frost-sullivan-israel-is-the-worlds-largest-exporter-of-unmannedaircraft/?goback=\%2Egde_65111_member_242681806

GE introduces miniature automatic video tracker and image stabiliser for unmanned vehicles, UAS Vision Daily News [online]. 2013 [cited 27 August 2013]. Available from Internet: http://www.uasvision.com/2013/08/27/ge-introduces-miniature-automatic-video-tracker-and-image-stabiliser-for-unmanned-vehicles

Gripen - an unmanned fighter?, Defence IQ Press [online]. 2013 [cited 10 July 2013]. Available from Internet: www. defenceiq.com

Hood tech's gyro-stabilised imaging systems for UAS, UAS Vision Daily News [online]. 2013 [cited 07 May 2013]. Available from Internet: http://www.uasvision. com/2013/05/07/hood-techs-gyro-stabilised-imaging-systems-for-uas/?utm_source $=$ Newsletter\&utm_medium $=$ email\&utm_campaign=e5024497c0-RSS_EMAIL_CAMPAIGN\&utm_term=0_799756aeb7-e5024497c0-297544857

Host, P. 2012. BAE systems converts 300th F-4 flying drone for the fir force, Unmanned Platforms. December.

Idaho Power Company. 2013. Monitoring Sensitive Salmon Populations on Snake River is Safer with Aeryon Scout ${ }^{\mathrm{Ta}}$ 
[online], [cited 30 August 2013]. Available from Internet: http://www.aeryon.com/applications/case-studies/588idaho-power-case-study.html?goback=\%2Egde_896357_ member_269589762\#\%21

Israeli Air Force now flying more unmanned than manned sorties, World Tribune [online]. 2013 [cited 10 July 2013]. Available from Internet: http://www.uasvision. com/2013/07/10/israeli-air-force-now-flying-more-unmanned-than-manned-soties/?utm_source $=$ Newsletter\&utm_medium=email\&utm_campaign=be30fa2105-RSS_ EMAIL_CAMPAIGN\&utm_term=0_799756aeb7-be30fa2105-297544857\#sthash.TmSwf4bM.dpuf

McCarthy, M. 2012. Boeing completes sea testing of unmanned little bird, Unmanned Platforms. December.

Micro-Epsilon Launches Lightweight Thermal Imaging Camera for UAVs [online]. 2013 [cited 18 July 2013]. Available from Internet: http://www.unmannedsystemstechnology.com/2013/07/micro-epsilon-launches-lightweight-thermal-imaging-camera-for-uavs/?goback= \%2Egde_896357_member_258738390\#sthash.v2XHt1kC. dpuf

Model helicopter decapitates teenager in Brooklyn park, UAS Vision Daily News [online]. 2013 [cited 09 September 2013]. Available from Internet: http://www.uasvision. com/2013/09/09/19-year-old-killed-by-model-helicopterin-brooklyn/

New OctoCopter from Tescorp in Colombia, UAS Vision Daily News [online]. 2013 [cited 13 May 2013]. Available from Internet: http://www.uasvision.com/2013/05/13/new-octocopter-from-tescorp-in-colombia/

Nigerian Air Force tests domestic-built UAS, UAS Vision Daily News [online]. 2013 [cited 10 September 2013]. Available from Internet: http://www.uasvision.com/2013/09/10/nigerian-air-force-tests-domestic-built-uas/?utm_source= Newsletter\&utm_medium=email\&utm_campaign $=$ 4682ece16e-RSS_EMAIL_CAMPAIGN\&utm_term = 0_799756aeb7-4682ece16e-297544857\#sthash.2uug9XkQ. dpuf

Silicon Sensing Systems. 2013. MEMS Inertial Sensor Solutions for Unmanned Vehicles [online], [cited 16 July 2013]. Available from Internet: http://www.unmannedsystemstechnology.com/2013/07/silicon-sensing-sytems/?goback=\%2Egde_896357_member_258134405

Oklahoma-based FireFlight fights fires with UAS, UAS Vision Daily News [online]. 2013 [cited 17 July 2013]. Available from Internet: http://www.uasvision.com/2013/07/17/ oklahoma-based-fireflight-fights-fires-with-uas/?utm source $=$ Newsletter\&utm_medium $=$ email\&utm_campaign=0ab07e59ff-RSS_EMAIL_CAMPAIGN\&utm_term= 0_799756aeb7-0ab07e59ff-297544857\#sthash.rSoRpzaX. dpuf

Poland to contribute $€ 40 \mathrm{M}$ to NATO UAS programme, Polska the Times. 2013, July.

Polish UAS to Assist U.K. Royal Navy [online]. 2013 [cited 09 September 2013]. Available from Internet: http://i-hls. com/2013/09/polish-uas-to-assist-u-k-royal-navy/?utm _ source $=$ rss\&utm_medium $=$ rss\&utm_campaign $=$ polish uas-to-assist-u-k-royal-navy\&utm_source=iHLS\&utm_ medium $=\mathrm{iHLS} \& u$ tm_campaign $=\mathrm{RSS} \# \% 21$

Roadmap for the Integration of Civil Remotely-Piloted Aircraft Systems into the European Aviation System: Final report. 2013. European RPAS Steering Group. June.

ScanEagle certified for arctic survey exploration, UAS Vision Daily News [online]. 2013 [cited 31 July 2013]. Available from Internet: http://www.uasvision.com/2013/07/31/ scaneagle-certified-for-arctic-survey-exploration

Single predator airframe exceeds 20.000 flight hours, UAS Vision Daily News [online]. 2013 [cited 01 July 2013]. Available from Internet: http://www.uasvision.com/2013/07/01/ single-predator-airframe-exceeds-20000-flight-hours

Sweetman, B. 2013. Unmanned system primes, suppliers' field new tech, Aviation Week \& Space Technology. September.

UAE and Russia to build UCAV based on helicopter, UAS Vision Daily News [online]. 2013 [cited 03 September 2013]. Available from Internet: http://www.uasvision. com/2013/09/03/uae-and-russia-to-build-ucav-based-onhelicopter/

UAS in Peru study ancient ruins, UAS Vision Daily News, [online]. 2013a. [cited 26 August 2013]. Available from Internet: http://www.uasvision.com/2013/08/26/uas-in-perustudy-ancient-ruins

UAS mounted spectrometers monitor barley and sugar beet crops in New Zealand, UAS Vision Daily News [online]. 2013b [cited 10 September 2013]. Available from Internet: http://www.uasvision.com/2013/07/10/uas-mounted-spectrometers-monitor-barley-suger-beet-crops-in-new-zealand

UAS to rescue avalanche victims, UAS Vision Daily News [online]. 2013c [cited 11 July 2013]. Available from Internet: http://www.uasvision.com/2013/07/11/uas-to-rescue-avalanche-victims

UN chooses Falco for Congo surveillance, UAS Vision Daily News [online]. 2013 [cited 16 August 2013]. Available from Internet: http://www.uasvision.com/2013/08/06/un-chooses-falco-fo-congo-surveillance

Unger, A. 2013. The birth of a new UAV mission, Israel Defense [online], [cited 13 January 2013]. Available from Internet: http://www.israeldefense.com/?CategoryID=472\&Article ID $=1900$

US Air Force studies future unmanned aircraft fleet mix, $U A V$ Vision Daily News [online]. 2013 [cited 05 July 2013]. Available from Internet: http://www.uasvision.com/2013/07/05/ us-air-force-studies-future-unmanned-aircraft-fleet-mix/

US Army expanding soldier attack options, Defence News [online]. 2013 [cited 07 May 2013]. Available from Internet: http://www.defensenews.com/article/20130507/DEFREG02/305060011/Special-Report-Precision-Strike?goback=\%2Egde_896357_member_248025519

U.S. Department of Transportation, Federal Aviation Administration. 2013. Unmanned Aircraft Systems (UAS) Operational Approval (8900.227). National Policy.

Vermeulen, C.; Lejeune, P.; Lisein, J., et al. 2013. Unmanned aerial survey of elephants, PLoS ONE 8(2), e54700. http://dx.doi.org/10.1371/journal.pone.0054700

Warwick, G. 2008. Cobham targets UAV-To-UAV refuelling milestone, Aviation Week. September.

Wilson, J. R. 2013a. UAV roundup, Aerospace America. July-August: 26-36.

Wilson, J. R. 2013b. Worldwide UAV roundup, Aerospace America Supplement. September. 